\title{
Predicting Capability of a Multiroom Fire Model
}

\section{KAZUHITO NAKAMURA}

Design Division

Shimizu Corporation

2-16-1 Kyobashi, Chuoh-ku, Tokyo 104, Japan

TAKEYOSHI TANAKA

Building Research Institute

Ministry of Construction

1, Tachihara, Tsukuba-shi, Ibaraki-ken 305, Japan

\section{ABSTRACT}

Several refinements were made on the two layers zone model previousIy developed by Tanaka in an attempt to provide an ongineering means to predict fire behavior in buildings. One of the refinement is that partial penetration model of upward and downward plumes across layer interfaces was introduced. By using this plume partial penetration model, the predicting capability of the multiroom fire spread model has been significantly refined.

Keyword : fire model, opening jet

\section{INTRODUCTTON}

For a performance based fire safety design method of buildings, user friendly computer model to predict smoke transport behavior in buildings is considered to be one of its indispensable elements. As such prediction models for smoke movement, chiefly two types of zone models have been developed by now, that is, one based on one layer concept and the other based on two layers concept.

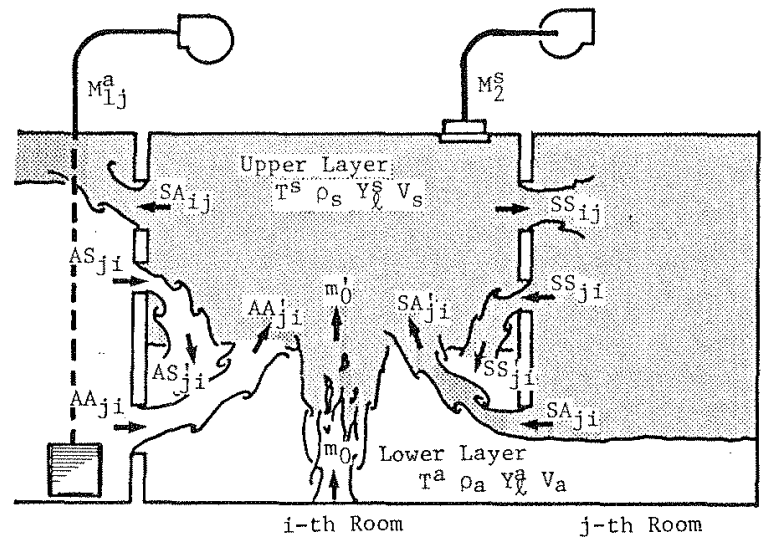

Fig.1 Concept of the two layers zone model 
However, many of these models, which have been developed primarily for a research purpose, will more or less need to be refined for the convenience of design practice as well as for the improvement in an accuracy to be used for design purposes. A multiroom smoke movement model(Ref.1), which is based on two layers concept, has been refined from this point of view. The points of refinement include, a) the prediction of lower layer properties, by which stack effect due to the temperature difference between inside and outside of building can be treated, b) capability of dealing with mechanical smoke control, c) time scheduled opening and closing of openings, by which the effects of door opening due to evacuation or window breaking due to fire on smoke novement can be assessed, d) capability of dealing with spaces of complex geometry such as a dome, and $e$ ) improvement of stability and speed up in numerical calculation.

Since most of the theoretical aspects of the model are given in Ref.2, this paper focuses on the model of the opening jet plume near an opening region.

\section{OPENING JET PLUME NEAR OPENING}

In this model, it is assumed that the plumes originated by a fire source and opening jets can penetrate through interfaces of the upper and lower layers, due to which exchanges of mass and heat take place. As a result the method to determine the fraction of mass and heat penetration becomes one of the key points. In the region far away from the source of an opening plume, i.e., opening jet, the fraction can be calculated by modeling opening jet plume as vertically rising plumes and assuming Gaussian profiles on the lateral profile of temperature and vertical velocity in a plume and criterion temperature of penetration (See Appendix).

In the region near an opening, however, simple application of Gaussian profile can cause a problem : i.e. temperature on the axis of modeled plune $\Delta \mathrm{T}_{0}$ can become higher than that of the opening jet $\Delta \mathrm{T}_{\mathrm{d}}$. This is illustrated by the example shown in Fig.3. In this example, an opening jet at $300 \mathrm{C}$ enters a lower layer at $20 \mathrm{C}$ and rises through the layer entraining the air and penetrates into an upper layer at $300 \mathrm{c}$. In this particular case, the excess temperature on the axis of the modeled plume exceeds the temperature difference between the opening jet and the ambient layer $\Delta \mathrm{T}_{\mathrm{d}}(=300-20=280 \mathrm{~K})$ in the region of $\mathrm{Z}<0.72 \mathrm{~m}$. So, if the criterion temperature for plume penetration is assumed as

$$
\Delta \mathrm{T}_{\mathrm{C}}=\left(\mathrm{T}_{\mathrm{S}}-\mathrm{T}_{\infty}\right) / 2=140(\mathrm{~K})
$$

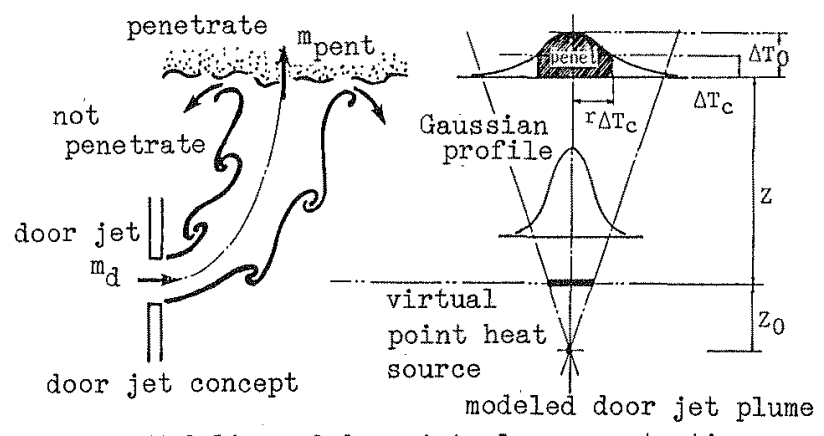

Fig.2 Modeling of door jet plume penetration 
the net heat gain of the upper layer becomes positive in the region of $Z$ $<0.25 \mathrm{~m}$ as is shown in Fig.3, so that the upper layer is heated while it has to be cooled in reality. Needless to say, this is attributed to the sharp peak of Gaussian profile of the temperature near axis, which is unrealistic in the sense that the plume axis temperature $\Delta \mathrm{T}_{0}$ exceeds the opening jet temperature $\Delta \mathrm{T}_{\mathrm{d}}$.

It will be more reasonable to consider that an opening jet initially has flat profiles of temperature and velocity, but the profiles collapse as the distance $Z$ increases and eventually turn into Gaussian profiles. Here an interim model is proposed as follows to deal with the penetration in the region near an opening.

Let $Z_{d}$ be the height where the excess temperature of the axis of a plume with a Gaussian profile $\Delta \mathrm{T}_{0}$ becomes equal to the temperature difference between the opening jet and the ambient layer $\Delta \mathrm{T}$. The near region to an opening is defined as the region where $Z<Z_{\mathrm{d}}$. It is assumed that the temperature profile of the off central part of a plume follows Gaussian profile with axis temperature $\Delta \mathrm{T}_{0}{ }^{\prime}$, and inner part takes flat temperature profile. Similar profile is assumed for the velocity profile being $W_{O}^{\prime}$ as the axis velocity of the plume. In other words,

$\Delta \mathrm{T}_{\mathrm{d}} / \Delta \mathrm{T}_{\mathrm{O}}^{\prime}=\exp \left(-\beta^{2} \eta_{\mathrm{d}}{ }^{2}\right)$

$W_{d} / W_{0}^{\prime}=\exp \left(-\eta_{d}^{2}\right)$
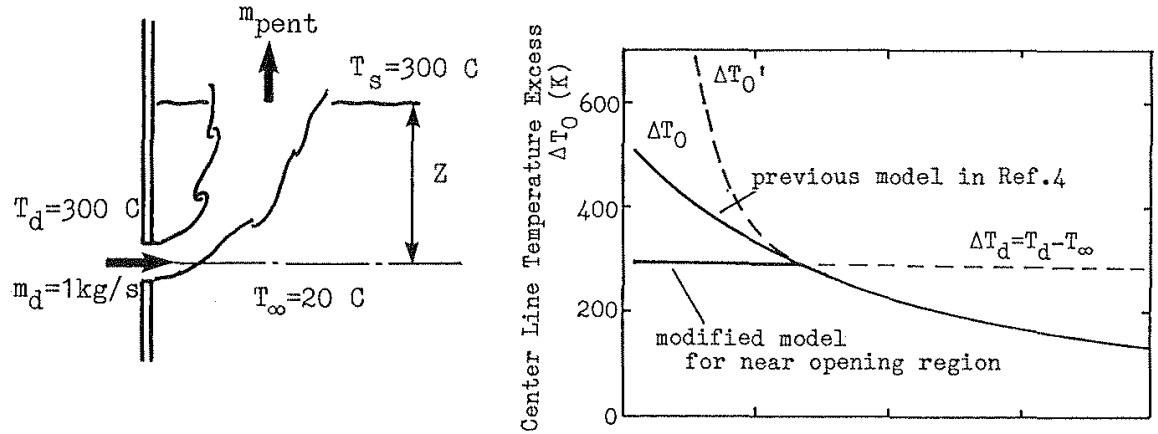

note :

$$
\begin{aligned}
Q_{\text {net }} & =q-C_{p} T_{s} m_{\text {pent }} \\
& =G_{p}\left(T_{\infty}-T_{s}\right) m_{\text {pent }}+k Q
\end{aligned}
$$

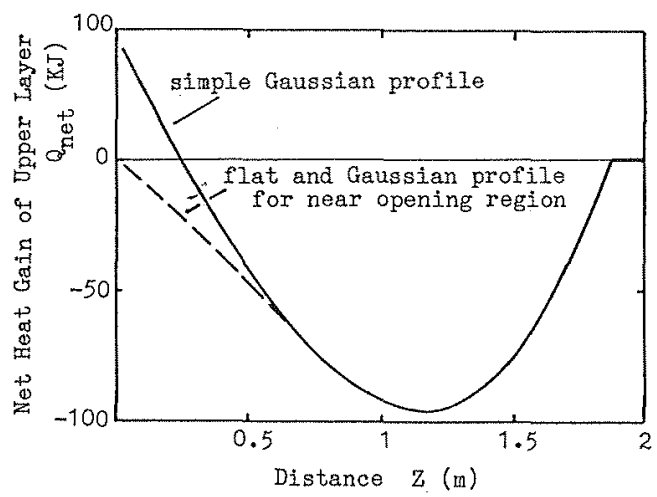

Fig.3 Effect of modified temperature and flow profile near opening region 


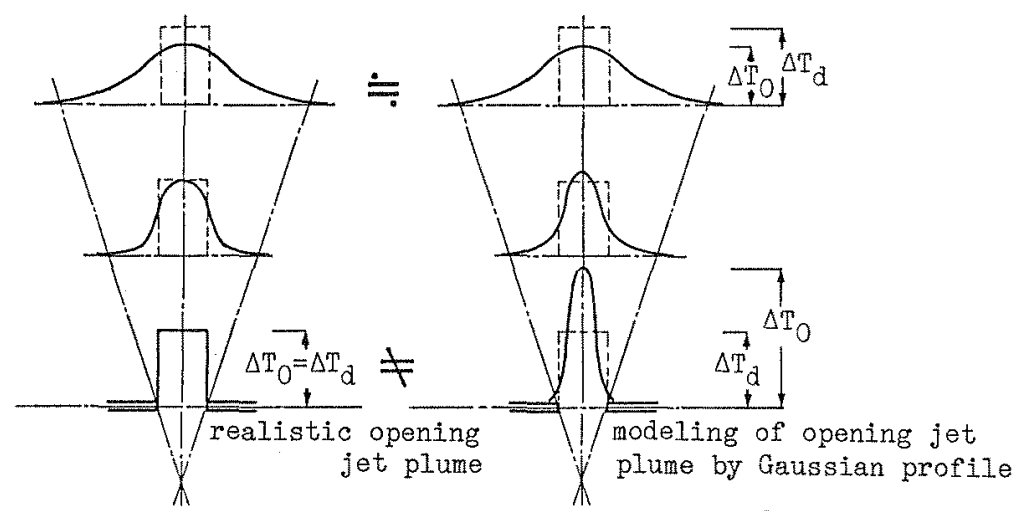

Fig.4 Limitation of modeling of opening jet plume by Gausian profile

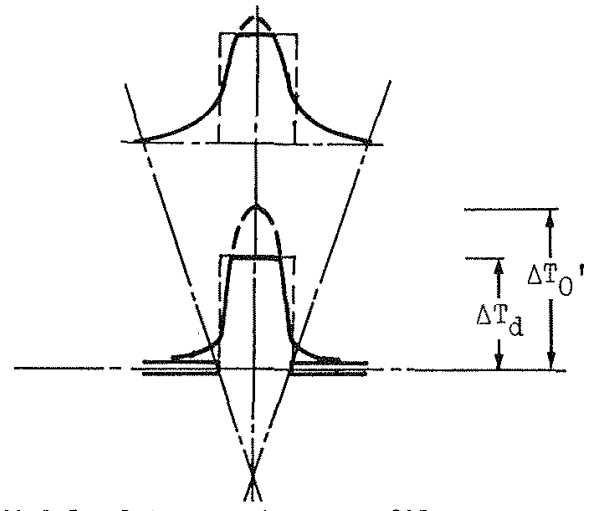

Fig.5 Model of temperature profile near opening region

where $\eta_{\mathrm{g}}$ is the radius in Howarth transformation which corresponds to $\Delta \mathrm{T}_{\mathrm{d}}$ on the Gaussian temperature profile.

Now, let $m_{z 1}$ be the mass flow rate through near axis area

$\left(0 \leq n \leq \eta_{d}\right), m_{z 2}$ be the rate through of $f$ axis area $\left(\eta_{d}<n\right)$ and $m_{z}$ be the total mass flow rate, then

$m_{z}=m_{z 1}+m_{z 2}$

$m_{z 1}=2 \pi \int_{0}^{\eta_{d}} w_{0}{ }^{\prime} \exp \left(-\eta_{d}^{2}\right) \rho_{\infty} b^{2} \eta d \eta$

$=\pi w_{0} \rho_{\infty} b^{2} \exp \left(-\eta_{d}^{2}\right) \eta_{d}^{2}$

$m_{z 2}=2 \pi \int_{\eta_{d}}^{\infty} W_{0}^{\prime} \exp \left(-n^{2}\right) \rho_{\infty} b^{2} \eta d \eta$

$=\pi W_{0} \rho_{\infty} b^{2} \exp \left(-n_{d}^{2}\right)$

Similarly, for the rate of heat flow through near and off axis regions, we have

$Q=Q_{1}+Q_{2}$ 


$$
\begin{aligned}
& Q_{1}=2 \pi C_{p} \int_{0}^{\eta_{d}} \Delta T_{0}{ }^{\prime} \exp \left(-\beta^{2} \eta_{d}^{2}\right) W_{0}{ }^{\prime} \exp \left(-\eta_{d}^{2}\right) \rho_{\infty} b^{2} \eta d \eta \\
& =\pi \mathrm{C}_{\mathrm{p}} \mathrm{W}_{0}{ }^{\prime} \rho_{\infty} \mathrm{b}^{2} \Delta \mathrm{T}_{0}{ }^{\prime} \exp \left(-\left(1+\beta^{2}\right) \eta_{\mathrm{d}}{ }^{2}\right) \eta_{\mathrm{d}}{ }^{2} \\
& \mathrm{Q}^{2}=2 \pi \mathrm{C}_{\mathrm{p}} \int_{\eta_{\mathrm{d}}}^{\infty} \Delta \mathrm{T}_{0}{ }^{\prime} \exp \left(-\beta^{2} \eta^{2}\right) W_{0}^{\prime} \exp \left(-\eta^{2}\right) \rho_{\infty} b^{2} n d \eta \\
& =\frac{\pi C_{p} W_{0} \cdot \rho_{\infty} b^{2}}{1+\beta^{2}} \Delta T_{0}^{\prime} \exp \left|-\left(1+\beta^{2}\right) \eta_{d}^{2}\right|
\end{aligned}
$$

From Eqs.(1)-(8) and (A3), $\eta_{d}$ can be obtained as follows:

$$
\eta_{\mathrm{d}}^{2}=\frac{1-\frac{1}{1+2}\left(\frac{\mathrm{z}+\mathrm{z}_{0}}{\mathrm{z}_{0}}\right)^{5 / 3}}{\left(\frac{\mathrm{z}+\mathrm{z}_{0}}{\mathrm{z}_{0}}\right)^{5 / 3}-1}
$$

Using $\eta_{d}^{2}$, the rate of mass penetrating through a layer interface is given as follows:

$$
\begin{aligned}
m_{\text {pent }} & =m_{z}-2 \pi \int_{\eta_{\Delta T c}}^{\infty} W_{0}{ }^{\prime} \exp \left(-n^{2}\right) \rho_{\infty} b^{2} \eta d \eta \\
& =m_{z}\left|1-\frac{1}{1+\eta_{d}^{2}} \exp \left(n_{d}^{2}-n_{\Delta T c}{ }^{2}\right)\right|
\end{aligned}
$$

where $\eta_{\Delta T C}{ }^{2}$ is the radius in Howarth transformation which corresponds to threshold temperature of penetration $\Delta \mathrm{T}_{\mathrm{C}^{*}}$. And the penetration rate of heat is given as

$$
\begin{aligned}
Q_{p} & =Q-2 \pi C p \int_{\eta_{\Delta T c}}^{\infty} \Delta T_{0}^{\prime} \exp \left(-\beta^{2} \eta^{2}\right) W_{0}^{\prime} \exp \left(-\eta^{2}\right) \rho_{\infty} b^{2} \eta d \eta \\
& =k Q
\end{aligned}
$$

where

$$
k=1-\frac{1}{1+\left(1+\beta^{2}\right) \eta_{d}^{2}} \exp \left\{\left(1+\beta^{2}\right)\left(\eta_{d}^{2}-\eta_{\Delta \mathrm{Tc}}^{2}\right)\right\}
$$

So, it follows that the penetration model near an opening has been obtained.

It should be kept in mind, however, that this theory is not perfect but of a compromised nature since the total mass flow rate have to be calculated using Eqs.(A1),(A2), i.e., the equations for the flow rate for far field region of plume with virtual point heat source as an adjusting parameter.

\section{SAMPLE CALCULATIONS}

In the followings, the results of two sample calculations are shown to demonstrate the computation capability of the present model.

Mechanical Smoke Exhaustion at Office Space

A series of field experiments for smoke behavior were conducted 
using the pavilions of the international exposition held at Tsukuba, 1985, taking advantage of the time lag between the closing of the fair and the pulling down of the pavilions.

of the pavilions in which fire experiments were run, IBM pavilion was provided with a mechanical smoke exhaustion system at its office area in compliance with The Building Standard Law. The office area used for the experiments consisted of an office with $51 \mathrm{~m}^{2}$ and a corridor of 1.75 $\mathrm{m}$ wide and $30 \mathrm{~m}$ long as is shown in Fig.6. The ceiling height of this area was $2.7 \mathrm{~m}$. One of the mechanical smoke vents was located at a corner of the office and the other at the end of the corridor and could exhaust smoke at the rate of $0.9 \mathrm{~m}^{3} / \mathrm{s}$ and $1.3 \mathrm{~m}^{3} / \mathrm{s}$, respectively.

The fire source was placed at the center of floor of the office. The fuel was methanol and the size of the source was $0.9 \mathrm{~m} \times 0.9 \mathrm{~m}$. The heat release rate was estimated as $320 \mathrm{~kW}$.

The predicted and the experimentally observed behavior of the smoke layers are shown in Fig.7 for the case with mechanical exhaustion at the office and the corridor(IBO2), and the case without mechanical

exhaustion(IB01). The figures schematically illustrates the section of. area and the left hand side and the right hand side represents the office and the corridor, respectively. The experimental temperature rise in the smoke layers in Fig.7 were obtained by thermocouple readings and are shown by the shades of different thickness according to the temperature. In the prediction, the corridor was divided into two parts because it was considerably long and had a turn at the middle.

In the case of no mechanical ventilation, the predicted layer temperatures are somewhat higher than those of measured, but generally speaking, the agreement of the predicted and experimentally obtained layer behavior can be said fair. In the case when the mechanical ventilation operated, both the prediction and the experiment demonstrate that the smoke can be effectively exhausted from the spaces by the smoke control system.

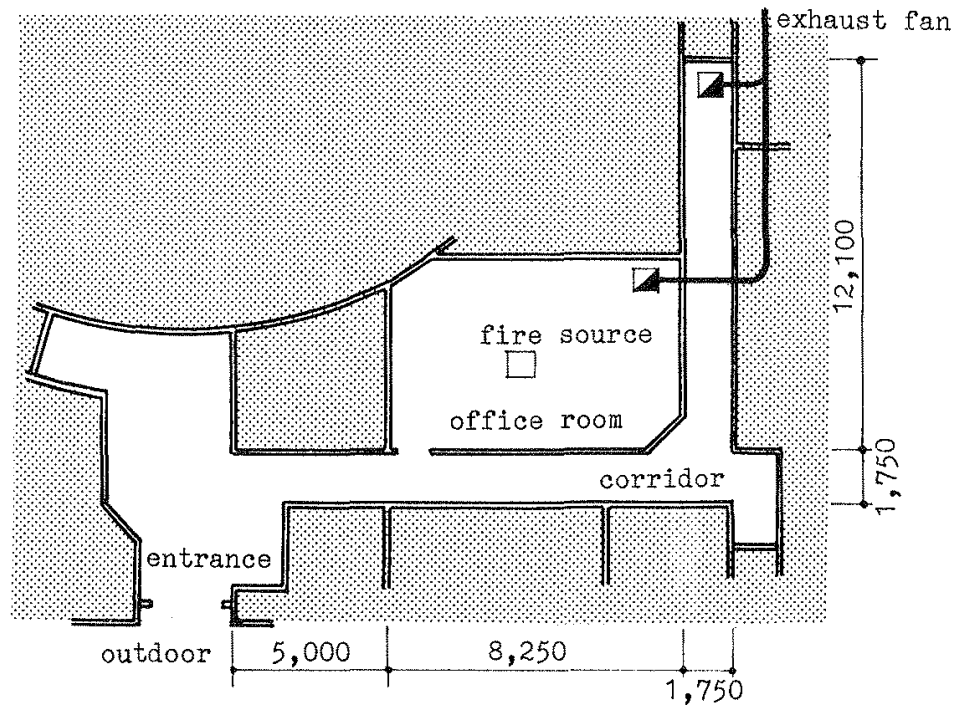

Fig.6 Area for the experiments in IBM pavilion 


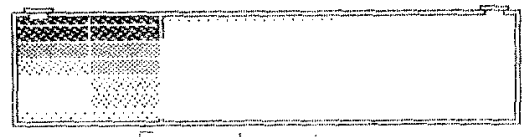

Experiment

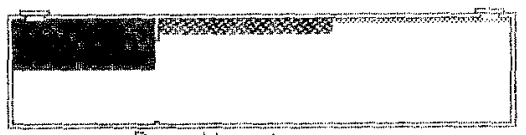

Prediction

No. T801 Tine $=60 \mathrm{sec}$.

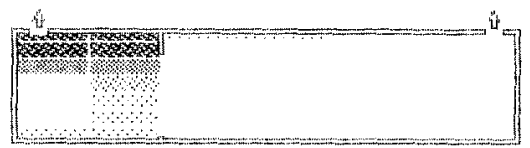

Evperiment

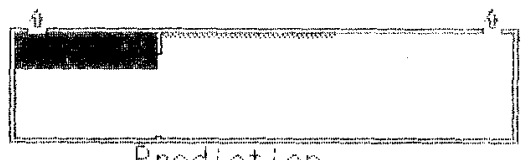

Prediotion

Mo. IBOZ Time $=00 \mathrm{sec}$.

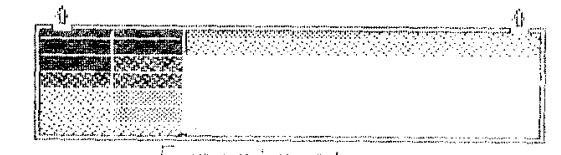

Eneriment

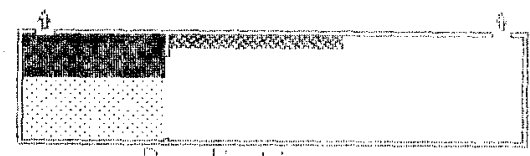

Predtotion

Ho. $180 \%$

Tine $=.100 \mathrm{sec}$

Terip. [deg.]

Fig.7 Predicted and experimental results of smoke behavior in IBM pavilion

Prediction of Smoke Movement in a Model Building

Prediction was attempted for the smoke movement for a eight story model building with an atrium. The building consists of an atrium of which size is $20 \mathrm{~m} \times 20 \mathrm{~m} \times 32 \mathrm{mH}$ and two rooms of $10 \mathrm{~m} \times 20 \mathrm{~m} \times 3 \mathrm{mH}$ on each floor. And on 3rd through 8th floor, two fire shutters, $5 \mathrm{~m} \mathrm{x} 3 \mathrm{mH}$ each, are installed on each opening facing to the atrium. On the top of the wall of the atrium is a natural smoke vent of $12 \mathrm{~m}$ wide and $1 \mathrm{~m}$ high, and on each floor an air supply fan with capacity $4 \mathrm{~m}^{3} / \mathrm{s}$ is equipped. The calculation was run under the scenario described as follows:

\begin{aligned} befime & \multicolumn{1}{c}{ event } \\ 0 sec. & $\begin{array}{l}\text { the outdoor and indoor temperature were } 30 \mathrm{C} \text { and } \\ \text { fire breaks out on the floor of the atrium (heat release } \\ \text { rate increase linearly from zero to } 5 \text { MW in } 300 \text { sec and } \\ \text { then levels off) } \\ \text { detects fire, evacuation starts throughout the building }\end{array} \\ 60$ sec. & $\begin{array}{l}\text { a window is opened at the office on } 7 \text { th floor } \\ \text { the fire shutters on each floor close but on } 5 \text { th and } 6 \text { th }\end{array} \\ 120$ sec. & $\begin{array}{l}\text { floor one of the two failed to close due to some trouble } \\ 125 \text { sec. mechanical air supply fan switches on at } 6 \text { th floor }\end{array} \\ 270$ sec. & the natural vent opens at the top of the atrium \end{aligned}

The results of the prediction are shown in Fig.9. 


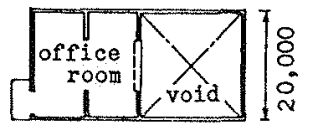

$$
\frac{10,000}{10,000} 20,000
$$

Plan

Fig.8 Outline of 8 story model building

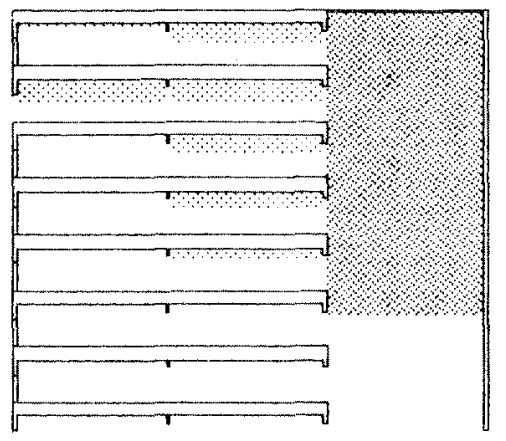

$\mathrm{Time}=120 \mathrm{sec}$.

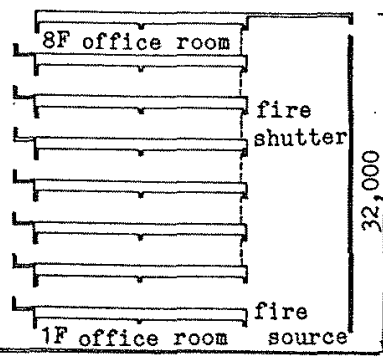

The temperatures of smoke layers are not yet very high but smoke begins to enter the rooms on each floors. On 7th floor, the smoke layers expands by mixing with the air flowing into the building through the opened window.

\section{$\mathrm{Time}=240 \mathrm{sec}$.}

The smoke layer in the atrium descends to near the bottom and the layer temperature rises to more than $50 \mathrm{c}$. The floors of which shutters are closed are kept comparatively safe, although some infiltration of smoke exists. On the floors of which fire shutters are not closed, significant amount of smoke fills the rooms.

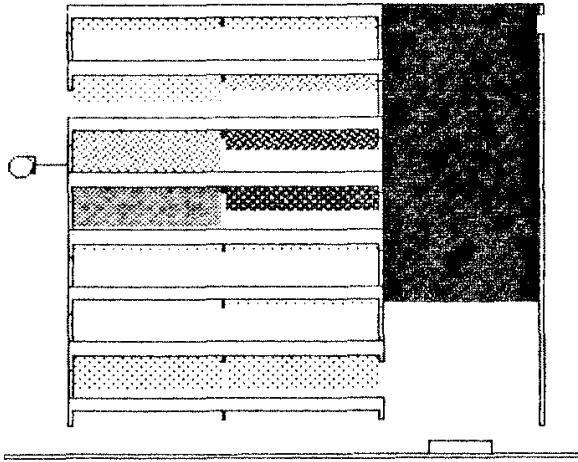

Time $=600 \mathrm{sec}$.

The smoke is gradualiy removed from the atrium through the natural vent. Hazardous condition develops on 5 th and 6 th floors, when the fire shutters failed to close, but the temperature of 6 th floor is somewhat lower than that of 5 th floor thanks to the mechanical air supply.

Fig.9 Smoke behavior in 8 story model building 


\section{CONGLUDING REMARKS}

We acknowledge that the models on the entrainment of an opening jet or the penetration of plumes are not based on very solid understanding of the phenomena, so we may have to be careful when we apply the model extensively to various problems.

It is obvious that engineering tools to predict fire behavior can help rationalize fire safety measures of buildings even if they are not perfect. In this sense, many of the existing models can be used in practical issues if sufficient attentions are paid on their limitations.

As for the present model, it is evaluated that with the introduction of partial penetration model of opening jets, the model is refined so that predict smoke movement in building can be predicted reasonably well without giving contradictory results. Also, the model is equipped with several features which are thought to be beneficial for design purposes.

The model still needs improvements on many respects, such as convective heat transfer, lateral smoke propagation along corridors, smoke behavior in narrow vertical shafts and so on, so we would like to continue its refinements absorbing better understandings on these phenomena as they grow.

\section{NOMENCLATURE}

Symbols

$\mathrm{b}$ transformed plume half width

$\mathrm{C}_{\mathrm{p}}$ specific heat of air $(\mathrm{kJ} / \mathrm{kg} / \mathrm{KK})$

$\mathrm{p}$ acceleration of gravity $\left(\mathrm{m} / \mathrm{s}^{2}\right)$

$\mathrm{k}$ fraction of the heat that penetrates into a layer

$m$ mass flow rate $(\mathrm{kg} / \mathrm{s})$

Q heat (kW)

$r$ plume radius $(\mathrm{m})$

T temperature (K)

$\Delta \mathrm{T}_{\mathrm{C}}$ criterion temperature difference for plume penetration $(K)$

$\Delta \mathrm{T}_{0}^{\mathrm{c}}$ temperature rise on a plume axis (K)

W plume velocity parallel to plure axis $(\mathrm{m} / \mathrm{s})$

$z_{0}$ distance of virtual point heat source from fire source (m)

$\beta$ ratio of Gaussian half widths of velocity and temperature profile

Subscript

$\eta$ plume radius in Howarth transformation

$p$ density $\left(\mathrm{kg} / \mathrm{m}^{3}\right)$

d denote door jet

pent denote penetration

$s$, a denote upper layer and lower layer

$\infty$ denote ambient

\section{REFERENCES}

1. Tanaka, T., A Model of Multiroom Fire Spread, NBSIR 83-2718(1983), NBS

2. Nakamura, K. and Tanaka, T., Refinement of A Multiroom Fire Spread model, The 2nd ASME--JSME Meeting on Thermal Engineering (1987), Hawaii 3. Cetegen, B.M., Zukoski, E. E. and Kubota, T., Entrainment and Flame Geometry of Fire Plumes, NBS-GCR-87-402(1982), NBS

4. Tanaka, T., A Proposed Model of Behavior of Plumes in Two Layer Models, 8th UJINR Joint Panel Meeting on Fire Safety(1985), BRI, Japan 5. Cooper, L.Y., Harkleroad, M., Quintiere, J. and Rinkinen, W., An 
Experimental Study of Upper Layer Stratification in Full-Size Multiroom Fire Scenarios, Journal of Heat Transfer Nov. 1982, Vol.104

\section{APPENDIX Formation of Plumes (Ref.2)}

The flow rate of fire plume is calculated using the formulas developed by Zukoski et al(Ref.3). Opening jet plumes are modeled as vertical thermal plumes and to calculate the flow rate of the plumes at the height of $Z$, the equation of plume flow rate for far field region by Zukoski et al(Ref.3) is also applied.

Virtual point heat source is assumed at a certain distance below an opening jet. The distance is given as

$z_{0}=\left[m_{d} /\left|0.21\left(\frac{g \rho_{\infty}^{2}}{C_{p} T_{\infty}}\right)^{1 / 3} Q^{1 / 3}\right|\right]^{3 / 5}$

where

$\mathrm{Q}=\mathrm{C}_{\mathrm{p}}\left|\mathrm{T}_{\mathrm{d}}-\mathrm{T}_{\infty}\right| \mathrm{m}_{\mathrm{d}}$

where $T_{d}$ and $T_{\infty}$ are the temperature of an opening jet and the ambient layer, and $m_{d}$ is the mass flow rate of the opening jet. With the use of $\mathrm{z}_{0}, \mathrm{~m}_{\mathrm{z}}$ is also expressed as

$\mathrm{m}_{\mathrm{z}}=\mathrm{m}_{\mathrm{d}}\left|\left(\mathrm{z}+\mathrm{z}_{0}\right) / \mathrm{z}_{0}\right| 5 / 3$

Gaussian profile is assumed on the vertical velocity of plume, then the mass penetration rate through a layer interface is given as

$m_{\text {pent }}= \begin{cases}\mathrm{m}_{\mathrm{z}}\left\{1-\exp \left(-\eta_{\Delta \mathrm{Tc}}{ }^{2}\right)\right\} & \left(\Delta \mathrm{T}_{\mathrm{c}}<\Delta \mathrm{T}_{0}\right) \\ 0 & \left(\Delta \mathrm{T}_{\mathrm{c}} \geq \Delta \mathrm{T}_{0}\right)\end{cases}$

where $\eta$ is plume radius in Howarth transformation. With as the critical temperature for penetration, $\eta_{\Delta T c}{ }^{2}$ is defined as

$\eta_{\Delta \mathrm{Tc}}{ }^{2}=-\left(1 / \beta^{2}\right) \ln \left(\Delta \mathrm{T}_{\mathrm{c}} / \Delta \mathrm{T}_{0}\right)$

where $\Delta \mathrm{T}_{0}$ and $\Delta \mathrm{T}_{\mathrm{C}}$ are given as

$\Delta \mathrm{T}_{0}=\left\{\Delta \mathrm{T}_{\infty} /\left(\mathrm{gC}_{\mathrm{p}}{ }^{2} \rho_{\infty}^{2}\right)\right\}^{1 / 3} \mathrm{Q}^{1 / 3}\left(\mathrm{Z}+\mathrm{Z}_{0}\right)^{-5 / 3}$

$\Delta \mathrm{T}_{\mathrm{C}}=\mathrm{C}\left(\mathrm{T}_{\mathrm{S}}-\mathrm{T}_{\mathrm{a}}\right)$

In Eq. (A7), $\mathrm{C}$ is a constant to be determined empirically.

Similar consideration is applied on the penetration of heat to yield

$Q_{\text {pent }}= \begin{cases}C_{p} m_{\text {pent }}+k Q & \left(\Delta \mathrm{T}_{c}<\Delta \mathrm{T}_{0}\right) \\ 0 & \left(\Delta \mathrm{T}_{\mathrm{c}} \geq \Delta \mathrm{T}_{0}\right)\end{cases}$

where

$\mathrm{k}=1-\exp \left(-\left(1+\beta^{2}\right) \eta_{\Delta \mathrm{Tc}}{ }^{2}\right)$ 